\title{
Vorwort zur 9. Auflage
}

Wir freuen uns sehr, dass unser Werk bislang so großen Zuspruch gefunden hat und nunmehr bereits in der 9. Auflage erscheint. Im Laufe der ersten sieben Auflagen konnten wir zahlreiche Verbesserungen vornehmen, nicht zuletzt dank der geistreichen Hinweise unserer Leser. ${ }^{1}$

Wir hoffen, dass auch die 9. Auflage unseren Leser:innen bei der Vorbereitung auf die mündliche Prüfung helfen wird und freuen uns weiterhin über Anregungen und Kritik (per E-Mail an: BasiswissenJura@degruyter.com), die wir auch in den künftigen Auflagen - soweit möglich - berücksichtigen werden.

Köln/Bonn, Juni 2021

RA Dr. Stephan Pötters, LL.M.

(Cambridge)

RA Dr. Christoph Werkmeister, LL.M. (Cambridge)

1 Die Autoren danken Herrn Kristian Kues für die Unterstützung bei der Überarbeitung des Werkes. 
